\title{
AVALIAÇÃO DA QUALIDADE E ATIVIDADE ANTIBACTERIANA DE EXTRATO DE PRÓPOLIS
}

\author{
EVALUATION OF QUALITY AND ANTIBACTERIAL ACTIVITY OF PROPOLIS \\ EXTRACT
}

\section{AVALIAÇÃO DE EXTRATOS DE PRÓPOLIS}

\author{
Cristina Peitz de Lima ${ }^{1}$ \\ Dayane Silva Bolino ${ }^{2}$ \\ Kelly Caroline Dionísio ${ }^{2}$ \\ Gabriela Santos de Miranda ${ }^{2}$ \\ Grayce Kelly Fernandes Maia ${ }^{2}$ \\ André Guilherme de Paula ${ }^{3}$ \\ Giuliano Kenro Alves de Campos ${ }^{4}$
}

RESUMO: A própolis é formada por material resinoso e balsâmico. É empregada pela humanidade para fins terapêuticos, pois possui ação anti-inflamatória, antibacteriana e antioxidante. O objetivo deste trabalho foi avaliar o padrão de identidade e qualidade de quatro extratos hidroglicólicos de própolis produzidos com propilenoglicol e água, por meio de análises sensoriais (aroma, cor, sabor e aspecto) e físico-químicas (extrato seco, cera, flavonoides, compostos fenólicos, atividade de oxidação, espectro de absorção UV-Vis, acetato de chumbo e hidróxido de sódio), bem como avaliar potencial antibacteriano dos extratos contra cepas de Staphylococcus aureus, Escherichia coli, Pseudomonas aeruginosa e Burkholderia cepacia. Os resultados obtidos foram comparados ao da Legislação Brasileira vigente referente aos extratos hidroalcoólicos e alcoólicos. Nenhuma das amostras analisadas atendeu todos os requisitos, tanto os sensoriais como os físico-químicos estabelecidos. Entretanto todas as amostras apresentaram atividade antibacteriana sobre as cepas utilizadas. Os resultados indicam que os extratos hidroglicólicos de própolis apresentam um padrão de identidade e qualidade diferente do que é estabelecido para extratos de própolis hidroalcoólicos e alcoólicos. Os extratos hidroglicólicos de própolis promoveram inibição do crescimento das bactérias gram-positivas e gram-negativas testadas. Mais estudos devem ser conduzidos para avaliar o potencial terapêutico dos extratos hidroglicólicos de própolis.

Palavras-chave: padrão de qualidade; atividade antibacteriana; propilenoglicol.

ABSTRACT: Propolis is formed by resinous and balsamic material. It is used by humanity for therapeutic purposes, as it has anti-inflammatory, antibacterial and antioxidant action. The objective of this research was to evaluate the identity and quality standard of four hydro glycolic extracts of propolis applied with propylene glycol and water, through sensory (aroma, color, flavor and appearance) and physical chemical analyzes (dry extract, wax, flavonoids, phenolics compounds, oxidation activity, UV-Vis absorption spectrum, lead acetate and sodium hydroxide), as well as to estimate the antibacterial potential of the extracts against strains of Staphylococcus aureus, Escherichia coli, Pseudomonas aeruginosa and Burkholderia cepacia. The results obtained were compared with the current Brazilian legislation regarding hydroalcoholic and alcoholic extracts. None of the analyzed analyzes met all requirements, both the sensors and the chemicals used. However, all samples showed antibacterial activity on the strains used. The results show that the propolis hydro glycolic extracts present a different identity and quality standard than that established for hydroalcoholic and alcoholic propolis extracts. Hydro glycolic extracts of propolis promote the inhibition of the growth of gram-positive and gram-negative bacteria. Further studies should be conducted to assess the therapeutic potential of hydro glycolic extracts of propolis.

Keywords: quality standard; antibacterial activity; propylene glycol.

\footnotetext{
${ }^{1}$ Doutora em Ciências Farmacêuticas e professora da Escola de Saúde do Centro Universitário Autônomo do Brasil - UniBrasil, Curitiba (PR).

${ }^{2}$ Acadêmica do curso de Farmácia no Centro Universitário Autônomo do Brasil - UNIBRASIL.

${ }^{3}$ Farmacêutico formado pelo Centro Universitário Autônomo do Brasil - UNIBRASIL.

${ }^{4}$ Farmacêutico da Toho laboratório Industrial de Cosméticos e Alimentos Nutricionais.
} 


\section{Cadernos da Escola de Saúde}

\section{INTRODUÇÃO}

O nome própolis é derivado do grego pro (em defesa) e polis (cidade), significando então, em defesa da cidade, no caso, a colmeia ${ }^{(1)}$. É utilizada pelas abelhas para revestir as paredes da colmeia, reforçar os favos, encher as fissuras, manter a temperatura ideal e restringir a entrada de estranhos. Além disso, também serve como proteção contra microrganismos e insetos, sendo considerado um desinfetante do interior da colmeia e dos alvéolos, mantendo-os assépticos para a postura da abelha rainha. É um antibiótico natural, evitando infecções e epidemias entre as abelhas ${ }^{(2)}$. Há tempos que a própolis vem sendo utilizada na medicina popular. Há registros que os egípcios, os gregos e os romanos já utilizavam-na há mais de 5000 anos com múltiplas finalidades ${ }^{(3)}$.

A própolis é uma mistura complexa, formada por material resinoso e balsâmico coletado pelas abelhas (Apis mellifera L.) dos ramos, flores, pólen, brotos e exsudados de árvores. Nas colmeias, as abelhas produzem a própolis com auxílio de enzimas e secreções salivares ${ }^{(4)}$. Sua composição é determinada principalmente pelas características fitogeográficas existentes ao redor da colmeia ${ }^{(5)}$, entretanto, a sazonalidade de uma mesma localidade pode causar a variação de sua composição ${ }^{(6)}$.

Para que a própolis possa ser utilizada, seja em uso medicinal ou como um alimento, seus constituintes solúveis devem ser extraídos com o uso de um solvente adequado. Existem vários tipos de solventes que podem ser utilizados nessa extração e a escolha depende das substâncias que se deseja extrair. A própolis bruta contém substâncias solúveis em óleo, em água e as que são solúveis tanto em óleo quanto em água ${ }^{(7)}$.

A própolis possui uma ampla aplicação medicinal, com propriedades antiinflamatórias que foram descritas principalmente contra doenças do sistema muscular, infecções, reumatismo e torções. É utilizada dermatologicamente na cicatrização de ferimentos, na regeneração de tecidos, no tratamento de queimaduras e em dermatites. $\mathrm{Na}$ odontologia é empregada na lavagem bucal para o tratamento de gengivites, quelite e na pósextração dentária. A substância apresenta propriedades antissépticas e adstringentes ${ }^{(8)}$.

A Instrução Normativa No 3, de 19 de janeiro de 2001, do Ministério da Agricultura, Pecuária e Abastecimento (MAPA) ${ }^{(9)}$ estabelece o regulamento de identidade e qualidade do extrato de própolis, solúveis em solução hidroalcóolica, álcool e água. O presente trabalho tem por objetivo realizar as análises determinadas pela Legislação Brasileira e estabelecer a identidade e os requisitos mínimos de qualidade de diferentes extratos hidroglicólicos de 


\section{Cadernos da Escola de Saúde}

própolis produzidos utilizando propilenoglicol e água, avaliando o potencial antibacteriano destes extratos.

\section{MATERIAL E MÉTODOS}

As amostras de extratos de própolis foram produzidas pela TOHO - Laboratório Industrial de Cosméticos e Alimentos Nutricionais Ltda. - por meio do processo de maceração a frio e micro-centrifugação em filtro de poliéster. Foi utilizada uma solução de propilenoglicol a $4 \%$ em água purificada como líquido extrator. Foram fornecidas quatro amostras de $250 \mathrm{~mL}$ de diferentes extratos hidroglicólicos de própolis, produzidos com amostras provenientes de diferentes locais dos estados do Paraná e de Santa Catarina. Os extratos de própolis foram identificados como A, B, C, e D. Os extratos A e B foram preparados com própolis verde com predominância de Alecrim (Baccharis dracunculifolia) e os extratos C e D foram preparados com própolis com predominância de Araucária (Araucaria angustifolia).

\subsection{REQUISITOS SENSORIAIS}

Foram observadas e anotadas características sensoriais como o aroma, a cor, o sabor e o aspecto das amostras analisadas. As análises dos requisitos sensoriais foram realizadas por 3 avaliadores e os resultados foram comparados com as especificações presentes na Instrução Normativa $\mathrm{N}^{\mathrm{o}}$ 3, de 19 de janeiro de 2001, do Ministério da Agricultura, Pecuária e Abastecimento (MAPA).

\subsection{REQUISÍTOS FÍSICO-QUÍMICOS}

Para a avaliação do padrão de identidade e qualidade do extrato de própolis, a Instrução Normativa $N^{\circ}$ 3, de 19 de janeiro de 2001, do Ministério da Agricultura, Pecuária e Abastecimento (MAPA) determina que sejam realizados ensaios físico-químicos quantitativos como: extrato seco, teor de cera, determinação de flavonoides e compostos fenólicos; e ensaios qualitativos como: teste de oxidação, espectro de absorção na região do UV-visível, teste de acetato de chumbo e teste de hidróxido de sódio.

\section{EXTRATO SECO}

Inicialmente placas de Petri permaneceram em estufa à $105^{\circ} \mathrm{C}$ por 1 hora. Depois, as placas foram transferidas para um dessecador até resfriamento. $\mathrm{O}$ peso de cada placa foi 


\section{Cadernos da Escola de Saúde}

determinado em balança analítica. Em cada placa de Petri foi adicionado $10 \mathrm{~mL}$ de cada amostra e verificado o peso. O conjunto (placa de Petri e extrato) foi colocado em estufa a $105^{\circ} \mathrm{C}$ até peso constante. Em seguida, as placas foram transferidas para um dessecador e após o resfriamento foram pesadas novamente. O resultado foi expresso em percentual $(\% \mathrm{~m} / \mathrm{v})$. As análises foram realizadas em triplicata ${ }^{(10)}$.

\section{TEOR DE CERA}

A quantidade de $10 \mathrm{~g}$ de cada amostra foi mantida a uma temperatura de $4^{\circ} \mathrm{C}$, por 8 horas. Após este período, foram retirados $5 \mathrm{~g}$ de cada amostra (P1) colocados em um béquer e filtrados em papel filtro previamente seco em estufa $\left(2\right.$ horas a $\left.105^{\circ} \mathrm{C}\right)(\mathrm{P} 2)$. Em seguida, o béquer e o papel filtro foram lavados com $5 \mathrm{~mL}$ de álcool etílico refrigerado, por três vezes. Depois de filtrado, o papel filtro foi seco em temperatura ambiente por 12 horas, sendo posteriormente colocado em estufa a $50^{\circ} \mathrm{C}$ por 15 minutos. Após o papel filtro ser retirado da estufa, foi colocado em dessecador e pesado (P3). A determinação do teor de cera de cada amostra foi dada pela seguinte fórmula ${ }^{(11)}$ : Cera $(\%)=$ P3 - P2 x 100 x P1.

\section{FLAVONOIDES}

O conteúdo total de flavonoides de cada amostra foi determinado a partir de $2 \mathrm{~mL}$ de cloreto de alumínio $2 \%(\mathrm{~m} / \mathrm{v})$ em metanol, misturado com $2 \mathrm{~mL}$ dos extratos hidroglicólicos de própolis. Em um espectrofotômetro a absorbância foi medida em 425 nm, após 10 minutos contra um branco. Uma curva analítica foi preparada com quercetina com concentrações entre 5 e $50 \mu \mathrm{g} / \mathrm{mL}$ utilizando o mesmo procedimento ${ }^{(12)}$. A equação da reta obtida foi utilizada para a determinação da concentração de flavonoides. Os ensaios foram realizados em triplicata.

\section{COMPOSTOS FENÓLICOS}

Para o doseamento dos compostos fenólicos das amostras, foi utilizado o reativo de Folin-Ciocalteau. Desta forma foi preparada uma curva analítica a partir de uma solução de ácido gálico utilizando concentrações entre 25 e $600 \mu \mathrm{g} / \mathrm{mL}$. Para cada tubo, adicionou-se $200 \mu \mathrm{L}$ de reativo de Folin-Ciocalteau, $160 \mu \mathrm{L}$ da solução de ácido gálico e 3,6 mL de água destilada, em seguida foi realizada agitação e esperou-se 3 minutos. Então, adicionou-se 0,4 $\mathrm{mL}$ de solução de carbonato de sódio $35 \%$ em cada tubo. Os tubos foram novamente agitados e deixados em repouso durante 60 minutos. O mesmo procedimento foi realizado com as amostras de extratos hidroglicólicos de própolis. A leitura foi realizada em espectrofotômetro 


\section{Cadernos da Escola de Saúde}

a $760 \mathrm{~nm}$, contra um branco. Com os resultados das absorbâncias do ácido gálico foi determinada a equação da reta que foi utilizada para a determinação da concentração de compostos fenólicos das amostras de extratos hidroglicólicos de própolis ${ }^{(13)}$. Os ensaios foram realizados em triplicata.

\section{ATIVIDADE DE OXIDAÇÃO}

Em um béquer de $100 \mathrm{~mL}$ foi preparada para cada amostra, uma solução com $2 \mathrm{~mL}$ da amostra e $48 \mathrm{~mL}$ de água destilada. Em um tubo de ensaio foram adicionados 0,5 $\mathrm{mL}$ dessa solução, $0,5 \mathrm{~mL}$ de água destilada e $1 \mathrm{~mL}$ de ácido sulfúrico 20\%. Após a mistura e resfriamento, adicionou-se $50 \mu \mathrm{L}$ de permanganato de potássio $0,1 \mathrm{~N}$. Foi observado o tempo para o desaparecimento da cor vermelha contra um fundo branco ${ }^{(11)}$. Os ensaios foram realizados em duplicata.

\section{ESPECTRO DE ABSORÇÃO NA REGIÃO DO UV-VIS}

O extrato de própolis deve apresentar picos característicos das principais classes de flavonoides entre 200 e $400 \mathrm{~nm}$. Para isso, diluiu-se cada amostra na proporção 1:1000, com propilenoglicol. As amostras diluídas foram submetidas à determinação do espectro de absorção com espectrofotômetro UV. O resultado foi considerado positivo quando a amostra apresentou um ou mais picos entre 250 a $350 \mathrm{~nm}^{(14)}$.

\section{TESTE DE ACETATO DE CHUMBO}

Foi adicionado $1 \mathrm{~mL}$ de cada amostra em um tubo de ensaio contendo $10 \mathrm{~mL}$ de acetato de chumbo a $10 \%$. A solução foi agitada e mantida em repouso por um período de 3 minutos. Foi considerado como positivo o aparecimento de precipitados amarelos homogêneos no fundo do tubo ${ }^{(11)}$.

\section{TESTE DE HIDRÓXIDO DE SÓDIO}

Foi adicionado $1 \mathrm{~mL}$ de cada amostra em tubo de ensaio contendo $10 \mathrm{~mL}$ de hidróxido de sódio a $50 \%$. A solução foi agitada e mantida em repouso por um período de 3 minutos. Foi considerado como positivo o aparecimento de precipitados brancos homogêneos em suspensão no tubo ${ }^{(11)}$. 


\section{Cadernos da Escola de Saúde}

\subsection{ANÁLISE ANTIBACTERIANA}

A análise da atividade antibacteriana foi realizada mediante o método de perfuração em ágar, baseado no Método de Fleming da escavação em valeta. Essa técnica de avaliação antibacteriana consiste na remoção de uma tira de ágar em formato cilíndrico, de modo a formar um poço, e nele é empregado o material de análise, neste caso, os extratos hidroglicólicos de própolis $(100 \mu \mathrm{L})^{(15)}$.

Inicialmente as cepas de Staphylococcus aureus (NEWP 0023), Escherichia coli (NEWP 0022), Pseudomonas aeruginosa (NEWP 0053) e Burkholderia cepacia (NEWP 0059), foram replicadas em caldo BHI (Brain Heart Infusion) e incubadas a $35^{\circ} \mathrm{C}$ por 24 horas. Após esse período, foram semeadas em ágar Mueller-Hinton e novamente incubadas a $35^{\circ} \mathrm{C}$ por 24 horas.

Preparou-se uma suspensão em $2 \mathrm{~mL}$ de salina estéril comparando com a turbidez do tubo número 0,5 da escala Mcfarland. Um swab estéril foi mergulhado na suspensão bacteriana, para retirar o excesso de líquido, pressionou-se o swab contra as paredes do tubo. Então, ele foi esfregado na superfície de cada placa de Petri contendo o meio ágar MuellerHinton em várias direções. Em seguida, foram feitas as perfurações no ágar e nelas foram adicionadas $100 \mu \mathrm{L}$ das amostras de extratos hidroglicólicos de própolis. As placas foram incubadas invertidas na estufa a $35^{\circ} \mathrm{C}$ por 24 horas. Passado este período, as placas foram retiradas da estufa e foram medidos os halos de inibição. Três controles foram realizados: o controle positivo de inibição (com o antibiótico gentamicina), controle do solvente utilizado para a produção dos extratos de própolis e controle de esterilidade do meio, em que duas placas foram incubadas nas mesmas condições do ensaio. $O$ teste foi realizado em duplicata $^{(16)}$.

\section{RESULTADOS E DISCUSSÃO REQUISITOS SENSORIAIS}

Na tabela 1, pode-se observar os resultados das características sensoriais das quatro amostras de extratos hidroglicólicos de própolis analisadas.

Todas as amostras apresentaram aroma característico de própolis, que podem variar de acordo com a origem botânica ${ }^{(9)}$, sendo a amostra A mais frutada, a amostra $\mathrm{C}$ mais adocicada e a amostra D mais amadeirada e picante.

As amostras A, B e D apresentaram coloração âmbar de diferentes intensidades, já a amostra $\mathrm{C}$ apresentou uma cor âmbar mais avermelhada. A característica da origem botânica 


\section{Cadernos da Escola de Saúde}

influencia na coloração do extrato de própolis que pode ser em tons de âmbar, avermelhada ou esverdeada ${ }^{(9)}$.

Em relação ao sabor, todas as amostras apresentaram sabores característicos de extrato de própolis, com algumas variações em relação a intensidade do sabor, a picância e o amargor.

No estudo de Funari ${ }^{(17)}$, os exames organolépticos frente a três amostras de própolis coletadas em apiário localizado no município de Cabreúva (SP) constataram que as amostras apresentaram aroma resinoso e balsâmico, cor esverdeada e sabor picante acentuado. O exame organoléptico da própolis merece atenção, pois pode indicar o caminho analítico a se seguir ou até mesmo permitir deduções prévias de algumas características físico-químicas da amostra. O mesmo autor afirma que, por exemplo, a própolis esverdeada (chamada green propolis), típica de algumas localidades da região sudeste do Brasil, é a mais bem cotada no mercado internacional, sugerindo que há uma relação entre sua cor e sua composição química, rica em ácidos fenólicos. Desta forma, uma boa análise organoléptica depende muito de sua fonte botânica. Os resultados encontrados pelo presente estudo sugerem que os extratos de própolis analisados são de boa qualidade em relação aos requisitos sensoriais, pois atendem a maioria das exigências, quanto a isso, do MAPA.

O aspecto de todas as amostras ficou diferente do padrão estabelecido pela Legislação Brasileira $^{(9)}$ para extratos hidroalcóolicos, que preconiza que os extratos devem apresentar-se como um líquido límpido e homogêneo, esse resultado pode ter interferência direta do líquido extrator utilizado, no caso, o propilenoglicol.

Tabela 1 - Resultados das análises sensoriais.

\begin{tabular}{ccccc}
\hline AMOSTRA & AROMA & COR & SABOR & ASPECTO \\
\hline A & $\begin{array}{c}\text { Característico/ } \\
\text { frutado }\end{array}$ & $\begin{array}{c}\text { Âmbar } \\
++\end{array}$ & $\begin{array}{c}\text { Característico/ } \\
\text { picante }\end{array}$ & $\begin{array}{c}\text { Turvo/com } \\
\text { precipitado }\end{array}$ \\
\hline B & Característico & $\begin{array}{c}\text { Âmbar } \\
+\end{array}$ & $\begin{array}{c}\text { Característico/ } \\
\text { suave/picante }\end{array}$ & $\begin{array}{c}\text { Turvo/com } \\
\text { precipitado }\end{array}$ \\
\hline C & $\begin{array}{c}\text { Característico/ } \\
\text { adocicado }\end{array}$ & $\begin{array}{c}\text { Avmbar } \\
\text { avermelhado } \\
+++\end{array}$ & $\begin{array}{c}\text { Característico/ } \\
\text { amargo/forte/ } \\
\text { picante/ } \\
\text { amadeirado }\end{array}$ & $\begin{array}{c}\text { Turvo/com } \\
\text { precipitado }\end{array}$ \\
\hline D & Característico/ & Âmbar & Característico/ & Turvo/com \\
\hline
\end{tabular}




\section{Cadernos da Escola de Saúde}

amadeirado/

picante forte/amargo

picante/amadeirado

\begin{tabular}{|c|c|c|c|c|}
\hline $\begin{array}{c}\text { Especificações } \\
\text { MAPA } \\
\text { (2001) }\end{array}$ & $\begin{array}{c}\text { Característico de } \\
\text { própolis, } \\
\text { dependendo da } \\
\text { origem botânica } \\
\text { (balsâmico e resinoso) }\end{array}$ & $\begin{array}{c}\text { Variada, } \\
\text { dependendo } \\
\text { da origem e da } \\
\text { concentração } \\
\text { (tons de âmbar, } \\
\text { avermelhada e } \\
\text { esverdeada) }\end{array}$ & $\begin{array}{c}\text { Característico, } \\
\text { de suave } \\
\text { a forte, } \\
\text { amargo } \\
\text { e picante }\end{array}$ & $\begin{array}{c}\text { Líquido } \\
\text { límpido } \\
\text { e } \\
\text { homogêneo }\end{array}$ \\
\hline
\end{tabular}

Legenda: (+) cor âmbar claro, (++) cor âmbar , (+++) cor âmbar escuro

Fonte: Os autores.

\section{REQUISITOS FÍSICO-QUÍMICOS}

$\mathrm{Na}$ tabela 2 demonstram-se os resultados das análises físico-químicas das quatro amostras de extratos hidroglicólicos de própolis analisadas.

Das amostras analisadas em relação ao teor de extrato seco, apenas a amostra D apresenta teor de sólidos acima de $11 \%$. Soares et al. ${ }^{(18)}$ analisaram amostras que também ficaram abaixo dos valores exigidos pela Legislação, encontrando resultados inferiores a $10 \%$. Já Gonsales et al. ${ }^{(19)}$ encontraram valores de extrato seco, para amostras de extrato alcóolico de própolis do estado de São Paulo, variando entre 8,05\% a 16,87\%. Em estudo de Souza et al. ${ }^{(20)}$ foram constatados valores na faixa de $9,6 \%$ a $17,1 \%$ para amostras da cidade de Botucatu (SP), levando em consideração as estações do ano e as diferentes técnicas de produção utilizadas. Segundo o mesmo estudo ${ }^{(20)}$, a própolis produzida no verão tende a apresentar maior porcentagem de extrato seco em comparação com as demais estações do ano. É a partir da concentração de $11 \%(\mathrm{~m} / \mathrm{v})$ de extrato seco que os extratos de alcoólicos e hidroalcóolicos de própolis possuem ação antibacteriana, fato pelo qual o MAPA recomenda a comercialização de extratos com no mínimo esse valor ${ }^{(21)}$.

O teor de cera em todas as amostras ultrapassou o limite máximo estabelecido de $1 \%$ em relação ao extrato seco. Woisky ${ }^{(22)}$ obteve resultados das amostras provenientes do estado de São Paulo e de Santa Catarina que possuíam 7,82\% e 6,79\% de teor de cera, respectivamente. Gregorio ${ }^{(23)}$ obteve resultados de teor de cera da cidade de Cajuru (SP) e encontrou valores de 7,44\% a 15,76\%. Lima ${ }^{(24)}$ observou resultados de teor de cera em várias cidades do Ceará, variando entre 1,7\% em Morro do Barriga III a 26,6\% em Timbira, que são resultados semelhantes aos encontrados na presente pesquisa. Lima ${ }^{(25)}$ afirma em sua pesquisa que a sazonalidade influencia na quantidade de cera presente nas própolis. A quantidade cera 


\section{Cadernos da Escola de Saúde}

elevada é a principal causa de turvação dos extratos de própolis, quando armazenados em baixas temperaturas ${ }^{(22)}$. Com isso, quanto maior o teor de cera, menor o teor de substâncias, como resinas e bálsamos, onde são encontrados os compostos responsáveis pelas ações terapêuticas $^{(14)}$.

Quanto ao teor de flavonoides, apenas a amostra A apontou valor acima de 0,25\%. Matsuda et al. ${ }^{(14)}$ determinaram o teor de flavonoides na região do Ivaí (PR) sendo de $0,309 \%$ e em Anitápolis (SC) o valor encontrado foi de $0,051 \%$. Lima $^{(24)}$ observou resultados de amostras provenientes do Estado do Ceará, no Morro da Barriga I, de 0,31\%, resultado semelhante ao da amostra A, e em Graça de 0,0272\%. Essa última ficando muito próximo ao valor da amostra D. Silva et al. ${ }^{(26)}$ constataram resultados entre $0,19 \%$ a $0,52 \%$. Estes estudos revelam que mesmo as amostras de extratos de própolis produzidas com álcool nem sempre atendem aos teores de flavonoides determinados na Legislação que preconiza no mínimo $0,25 \%$ de flavonoides ${ }^{(9)}$.

Os compostos fenólicos são substâncias não sintetizadas pelo organismo humano que, quando ingeridas na dieta em quantidades significativas, contribuem para a prevenção de doenças graves como alguns tipos de câncer, cardiopatias, distúrbios metabólicos, doenças neurodegenerativas e enfermidades inflamatórias ${ }^{(27-28)}$. Quanto ao teor de compostos fenólicos nos extratos de própolis, a Legislação Brasileira para extratos alcoólicos e hidroalcóolicos exige no mínimo $0,5 \%{ }^{(9)}$, mas, como podemos observar na Tabela 2 , nenhuma das amostras analisadas atingiu esse mínimo, indicando que o líquido extrator hidroglicólico apresenta uma menor capacidade de extração de compostos fenólicos. Segundo Kawakita et al. ${ }^{(1)}$, a porcentagem de compostos fenólicos foi de $0,52 \%$ e $0,53 \%$ para duas amostras de extrato de própolis analisadas. Matsuda et al. ${ }^{(14)}$ observaram que todas as amostras analisadas atingiram o mínimo necessário estipulado pela Legislação, ficando entre 0,515\% em Anitápolis (SC) e $1,280 \%$ em Ivaí (PR). Lima ${ }^{(24)}$ analisou os teores de flavonoides de extratos de própolis obtidos de algumas cidades do Ceará e os resultados foram de 0,02\% em Aguiar e 1,71\% em Morro da Barriga I. A sazonalidade é um fator importante para colheita de própolis com altos teores de compostos fenólicos, pois em estações chuvosas o número de espécies botânicas em estado vegetativo é muito maior do que quando comparado ao período $\operatorname{seco}^{(24)}$.

O teste de oxidação é um parâmetro utilizado frequentemente para sugerir o tempo decorrido desde a colheita da própolis, o tipo de armazenamento e a atividade antioxidante da amostra. Altos índices de oxidação no extrato de própolis podem indicar um longo período de armazenamento em temperaturas elevadas, seja no interior da colmeia ou em depósitos de 


\section{Cadernos da Escola de Saúde}

armazenamento $^{(29)}$. Das amostras analisadas, todas passaram pelo teste determinado pelo MAPA, obedecendo ao padrão de qualidade para a comercialização dos extratos de própolis. Desta forma, a própolis produzida e utilizada para preparo dos extratos, pode ser considerada de boa qualidade, mantendo sua viabilidade. Lima ${ }^{(25)}$ encontrou dados para o índice de oxidação entre 1,5 e 4,5 segundos para as própolis analisadas. Matsuda et al. ${ }^{(14)}$ também observaram que na região sul do Brasil, assim como nas amostras analisadas na presente pesquisa, todos os resultados ficaram abaixo de 22 segundos.

Quanto ao espectro de absorção no UV-VIS, os extratos de própolis devem apresentar picos característicos das principais classes de flavonoides entre 200 e $400 \mathrm{~nm}^{(9)}$. Todas as amostras analisadas atenderam a este quesito. Toreti ${ }^{(30)}$ avaliou extratos de própolis na cidade de Água de São Pedro (SP) e obteve espectros de absorção e comprimento de onda entre 282 e 299nm. Lima ${ }^{(24)}$ analisou as amostras que apresentaram comprimento de onda de 270 a 330nm, perfil característico de presença de flavonoides e de fenóis. A absorção no UV-Vis é um dos parâmetros químicos mais utilizados para classificar e avaliar os extratos de própolis, pois as atividades terapêuticas têm sido atribuídas a compostos fenólicos como flavonoides, ácido caféico, ácido cinâmico e derivados ${ }^{(24)}$.

Como provas qualitativas, que visam a identificação dos constituintes de uma determinada amostra, foram realizados os testes com o acetato de chumbo e o hidróxido de sódio. A análise do acetato de chumbo verifica a homogeneidade das partículas do extrato de própolis em meio a um sal e a do hidróxido de sódio verifica a homogeneidade das partículas do extrato de própolis em meio a uma base. Todos os extratos analisados na presente pesquisa apresentaram resultado positivo para acetato de chumbo, estando de acordo com a norma regulamentadora $^{(9)}$. Resultados semelhantes foram obtidos por Kawakita et al. ${ }^{(11)}$, em que todas as amostras também foram positivas para o acetato de chumbo. Quanto ao hidróxido de sódio, todas as amostras deram negativas.

Foi verificado na presente pesquisa que as amostras de extratos hidroglicólicos de própolis analisadas apresentam um padrão de identidade e qualidade diferente do que é determinado pelo MAPA para extratos alcóolicos e hidroalcóolicos. Justifica-se estes resultados com o solvente empregado na produção dos extratos de própolis da presente pesquisa, a fração propilenoglicol e água. A Instrução Normativa $\mathrm{N}^{\circ} 3$, de 19 de janeiro de 2001, do MAPA estabelece que o extrato de própolis é composto de elementos solúveis da própolis em solução hidroalcoólica, álcool e água.

Os solventes são utilizados para extrair os princípios ativos da própolis, ou seja, aqueles presentes nas partes resinosa e balsâmica. Após essa extração e da separação do 


\section{Cadernos da Escola de Saúde}

extrato líquido, sobra a borra de própolis, que é constituída pelos componentes que não são solúveis naquele determinado solvente. A extração alcoólica e hidroalcóolica extrai da própolis mais quantidade de flavonoides, comparado aos demais solventes ${ }^{(3)}$. Longhini $^{(31)}$, em seu estudo, observa que os extratos hidroglicólicos de própolis mantêm certa linearidade, pois de acordo com a diminuição da concentração do propilenoglicol, o teor de flavonoides totais também diminui. A priori, o solvente glicol não seria recomendado como eficiente para a própolis, devido ao baixo teor de flavonoides obtido. Este fato pode ser explicado pois a própolis é um material resinoso, insolúvel em água. Os glicóis melhoram a extração das substâncias flavonóidicas em relação à água pura, mas não em comparação ao álcool e suas diluições, quando o material a ser extraído é uma resina ${ }^{(31)}$. Por isso foi observado que os teores de flavonoides de extratos hidroglicólicos de própolis foram inferiores ao estabelecidos pela norma do MAPA para extratos alcoólicos e hidroalcoólicos ${ }^{(9)}$. Outra justificativa para os valores de flavonoides e compostos fenólicos encontrados nos extratos hidroglicólicos testados é o teor de propilenoglicol de $4 \%$ no líquido extrator. A água é uma substância polar que apresenta um menor poder de penetração na própolis. Desta forma, a predominância da água no solvente utilizado no preparo das amostras dificulta a extração de flavonoides e compostos fenólicos.

Os extratos glicólicos e hidroglicólicos são muito empregados na indústria de cosméticos e fitocosméticos devido à propriedade emoliente. O propilenoglicol em solução tem a capacidade de extrair substâncias aromáticas e hidrossolúveis como taninos e flavonoides. Já o álcool etílico como solvente, apesar de muito eficiente, promove um efeito desidratante que pode causar o ressecamento da pele e cabelos ${ }^{(32)}$. Por isso é importante realizar estudos que avaliem o potencial de extratos glicólicos de própolis.

Com os resultados obtidos, não podemos afirmar que as amostras analisadas na presente pesquisa ficaram fora dos requisitos apenas pelo uso da mistura de propilenoglicol e água purificada como solvente extrator. $\mathrm{O}$ que se verifica é que a normativa se baseia em extratos alcoólicos e hidroalcoólicos de própolis, podendo assim justificar os resultados obtidos. Quando se utiliza o álcool como solvente, a borra de própolis que sobra, após a extração, apresenta atividade farmacológica pequena ou nula ${ }^{(3)}$, resultados que ainda não foram comprovados com a extração por propilenoglicol. É importante destacar que diversos pesquisadores relatam que, mesmo em extratos de própolis produzidos com álcool e mistura de água e álcool, os parâmetros de identidade e qualidade muitas vezes não são atingidos . Podemos destacar Mariano ${ }^{(3)}$ que salienta, de uma maneira geral, que os processos de 
produção de extrato de própolis não são padronizados, que as empresas trabalham com as condições que consideram mais convenientes ao seu orçamento operacional, mas nem sempre essas condições apresentam um bom aproveitamento e de acordo com Gonsales ${ }^{(19)}$, os resultados demonstram a necessidade de padronização nas técnicas de produção de própolis bem como capacitação técnica dos produtores quanto às Boas Práticas de Produção e comercialização da própolis. Desta forma possivelmente a qualidade seria atingida.

Tabela 2 - Resultados das análises físico-químicas.

\begin{tabular}{|c|c|c|c|c|c|}
\hline & $\begin{array}{c}\text { AMOSTRA } \\
\text { A }\end{array}$ & $\begin{array}{c}\text { AMOSTRA } \\
\text { B } \\
\end{array}$ & $\begin{array}{c}\text { AMOSTRA } \\
\text { C }\end{array}$ & $\begin{array}{c}\text { AMOSTRA } \\
\text { D } \\
\end{array}$ & $\begin{array}{l}\text { Especificações } \\
\text { (MAPA 2001) }\end{array}$ \\
\hline $\begin{array}{c}\text { Extrato seco } \\
\%(\mathrm{~m} / \mathrm{v})\end{array}$ & 8,58 & 1,98 & 9,69 & 12,56 & $\begin{array}{c}\text { Mínimo de } 11 \% \\
(\mathrm{~m} / \mathrm{v})\end{array}$ \\
\hline $\begin{array}{c}\text { Cera \% } \\
(\mathbf{m} / \mathbf{m})\end{array}$ & 2,6 & 2,56 & 6,76 & 20,38 & $\begin{array}{l}\text { Máximo } 1 \% \text { do } \\
\text { extrato seco } \\
(\mathbf{m} / \mathbf{m})\end{array}$ \\
\hline $\begin{array}{c}\text { Flavonoides } \\
\%(\mathrm{~m} / \mathrm{m}) \\
\pm \mathrm{DP} \\
\end{array}$ & $\begin{array}{c}0,31 \\
\pm 0,002082\end{array}$ & $\begin{array}{c}0,06 \\
\pm 0,001\end{array}$ & $\begin{array}{c}0,16 \\
\pm 0,000577\end{array}$ & $\begin{array}{c}0,03 \\
\pm 0,000577\end{array}$ & $\begin{array}{c}\text { Mínimo } \\
0,25 \% \\
(\mathrm{~m} / \mathrm{m}) \\
\end{array}$ \\
\hline $\begin{array}{c}\text { Compostos } \\
\text { Fenólicos } \\
\%(\mathrm{~m} / \mathrm{m}) \\
\end{array}$ & $\begin{array}{c}0,46 \\
\pm 0,000577\end{array}$ & $\begin{array}{c}0,32 \\
\pm 0,005196\end{array}$ & $\begin{array}{c}0,44 \\
\pm 0,007506\end{array}$ & $\begin{array}{c}0,29 \\
\pm 0,000577\end{array}$ & $\begin{array}{c}\text { Mínimo } \\
\mathbf{0 , 5 0 \%} \\
(\mathbf{m} / \mathbf{m}) \\
\end{array}$ \\
\hline $\begin{array}{c}\text { Teste } \\
\text { de } \\
\text { oxidação }\end{array}$ & $\begin{array}{c}\text { inferior a } \\
22 \\
\text { segundos }\end{array}$ & $\begin{array}{l}\text { inferior a } \\
22 \\
\text { segundos }\end{array}$ & $\begin{array}{l}\text { inferior a } \\
22 \\
\text { segundos }\end{array}$ & $\begin{array}{l}\text { inferior a } \\
22 \\
\text { segundos }\end{array}$ & $\begin{array}{l}\text { Máximo } \\
22 \\
\text { segundos }\end{array}$ \\
\hline $\begin{array}{c}\text { Espectro de } \\
\text { absorção no } \\
\text { UV-visível }\end{array}$ & + & + & + & + & $\begin{array}{c}\text { Banda de } \\
\text { absorção entre } \\
\text { 250nm a 400nm }\end{array}$ \\
\hline $\begin{array}{l}\text { Acetato de } \\
\text { Chumbo }\end{array}$ & + & + & + & + & $\begin{array}{c}\text { Precipitados } \\
\text { amarelos e } \\
\text { homogêneos no } \\
\text { fundo do tubo }\end{array}$ \\
\hline $\begin{array}{l}\text { Hidróxido } \\
\text { de sódio }\end{array}$ & - & - & - & - & $\begin{array}{c}\text { Precipitados } \\
\text { brancos e } \\
\text { homogêneos em } \\
\text { suspensão no } \\
\text { tubo } \\
\end{array}$ \\
\hline
\end{tabular}

Legenda: (+) positivo, (-) negativo

Fonte: Os autores. 


\section{Cadernos da Escola de Saúde}

\section{ANÁLISE ANTIBACTERIANA}

$\mathrm{Na}$ Tabela 3 é possível verificar a atividade antibacteriana das amostras de extratos hidroglicólicos de própolis testadas. Todas as amostras apresentaram atividade nos quatro microrganismos utilizados. O antibiótico gentamicina foi escolhido para ser o controle positivo de inibição e produziu ação antibacteriana nos microrganismos utilizados, como o esperado, em bactérias gram-positivas e gram-negativas.

A $S$. aureus é uma bactéria esférica, do grupo dos cocos gram-positivos, frequentemente encontrada na pele e nas fossas nasais de pessoas saudáveis, entretanto pode provocar doenças, que vão desde simples até graves infecções ${ }^{(33)}$. Dentre as amostras analisadas, as que apresentaram maior atividade antibacteriana sobre a $S$. aureus foram as amostras A, B e C.

A E. coli pertence a um grupo de bactérias gram-negativas que residem normalmente no intestino de pessoas saudáveis, mas algumas cepas podem causar infecção nos tratos digestivo e urinário ou em outras partes do organismo ${ }^{(34)}$. A amostra A foi a amostra que apresentou maior atividade antibacteriana sobre a $E$. coli, quando comparada com as outras amostras analisadas, que também apresentaram alguma atividade.

A $P$. aeruginosa é uma bactéria gram-negativa, baciliforme e aeróbia. A maior parte das infecções causadas por esta bactéria é em pacientes hospitalizados, em particular em pessoas debilitadas ou imunocomprometidas, sendo uma causa comum de infecções em $\mathrm{UTI}^{(35)}$. As amostras A e B apresentaram melhor atividade antibacteriana sobre a $P$. aeruginosa, seguidas da amostra $\mathrm{C}$, que também apresentou uma considerável atividade.

Já a $B$. cepacia é uma espécie de bactéria patogênica oportunista gram-negativa do sistema respiratório em pacientes hospitalizados (síndrome cepacia), especialmente em pacientes com fibrose cística ${ }^{(36)}$. As amostras que apresentaram melhores resultados antibacterianos sobre a B. cepacia foram as amostras A e C.

De acordo com Silva et al. ${ }^{(26)}$, que realizaram análises avaliando a atividade antimicrobiana de extrato de própolis oriundo estado da Paraíba, por meio da técnica de perfuração/escavação de poços em ágar, verificou-se que os extratos etanólicos de própolis utilizados não inibiram o crescimento de $S$. aureus, não sendo verificada a atividade antibacteriana da própolis sobre essa cepa, evidenciando que a sazonalidade da colheita, os diferentes locais e extratos influenciam em resultados distintos em relação à atividade antibacteriana. 


\section{Cadernos da Escola de Saúde}

Entretanto Gomes et al. ${ }^{(37)}$, realizando estudo da própolis bruta oriunda do município de Terenos (MS), constataram atividade antibacteriana positiva em relação ao extrato alcoólico de própolis, por meio da mesma técnica de perfuração de poços em ágar, verificando que o extrato alcoólico de própolis apresentou atividade antibacteriana para todas as bactérias gram-positivas e gram-negativas utilizadas na pesquisa, entre elas a $S$. aureus, a E. coli e $P$. aeruginosa, assim como na presente pesquisa.

Kawakita et al. ${ }^{(11)}$, utilizando técnica da diluição em caldo para determinação da concentração inibitória bactericida e semeadura em meio sólido para a concentração inibitória mínima, verificaram que o extrato alcoólico de própolis obtido de Botucatu (SP) demonstraram atividade sobre $S$. aureus e E. coli independente da temperatura de armazenamento do extrato. Em outro estudo, Junior et $a l^{(38)}$ avaliaram a atividade antimicrobiana do extrato de própolis sobre $S$. aureus, Enterococcus sp, E. coli, P. aeruginosa e Candida albicans. Verificou-se que a atividade antimicrobiana variou de acordo com o local em que a amostra de própolis foi produzida, sendo as bactérias gram-positivas ( $S$. aureus e Enterococcus $s p$ ) e $C$. albicans mais susceptíveis à própolis obtida na região de Botucatu, enquanto para as gram-negativas, a amostra de Urubici (SC) foi a mais eficiente sobre $E$. coli e a de Mossoró ( $\mathrm{RN})$ para $P$. aeruginosa. As bactérias gram-positivas foram mais sensíveis ao extrato alcóolico de própolis, independentemente do local de coleta.

Em estudo de Maia-Araújo ${ }^{(39)}$, realizando as análises com duas técnicas para avaliar a ação antibacteriana, a técnica dos poços e a técnica de difusão em disco, verificou-se que a amostra de própolis vermelha, coletada em um apiário localizado no município de Brejo Grande (SE), apresentou atividade antibacteriana em ambas as técnicas frente a $S$. aureus.

Apesar de alguns dos resultados das análises sensoriais e físico-químicas dos extratos hidroglicólicos de própolis serem diferentes das especificações do MAPA, as amostras analisadas apresentaram resultados satisfatórios na ação antibacteriana.

Tabela 3 - Resultados da análise antibacteriana.

\begin{tabular}{ccccc}
\hline AMOSTRA & $\begin{array}{c}\text { S. aureus } \\
\text { halo de } \\
\text { inibição }(\mathbf{m m})\end{array}$ & $\begin{array}{c}\text { E. coli } \\
\text { halo de } \\
\text { inibição }(\mathbf{m m})\end{array}$ & $\begin{array}{c}\text { P. aeruginosa } \\
\text { halo de } \\
\text { inibiçãa }(\mathbf{m m})\end{array}$ & $\begin{array}{c}\text { B. cepacia } \\
\text { halo de } \\
\text { inibição }(\mathbf{m m})\end{array}$ \\
\hline A & 25 & 28,5 & 25 & 27 \\
B & 24 & 21,5 & 25 & 24 \\
C & 24 & 20,5 & 23 & 27 \\
\end{tabular}




\section{Cadernos da Escola de Saúde}

D

20,5
15
19,5
21

\begin{tabular}{llllc} 
Gentamicina & 35,5 & 54 & 46 & 57,5 \\
\hline
\end{tabular}

Fonte: Os autores.

\section{CONCLUSÃO}

Os extratos glicólicos de própolis produzidos com propilenoglicol apresentaram resultados diferentes dos requisitos do MAPA para extrato de própolis alcoólico e hidroalcoólico. Os extratos glicólicos e hidroglicólicos são muito utilizados em indústrias cosméticas por serem menos agressivos na pele que extratos alcoólicos. No presente estudo observou-se que os diferentes extratos hidroglicólicos apresentaram significativa atividade antimicrobiana, tanto em bactérias gram-positivas quanto em gram-negativas. Uma vez que não há monografia oficial para extratos hidroglicólicos de própolis, existe uma demanda de informações sobre os requisitos de identidade e qualidade destes extratos. Desta forma, mais estudos devem ser conduzidos para avaliar o potencial terapêutico e os requistos de qualidade dos extratos glicólicos de própolis.

\section{REFERÊNCIAS BIBLIOGRÁFICAS}

[1] Ghisalberti, EL. Propolis: a review - Foundation of Japanese food analysis center, $\mathrm{n}^{\mathbf{o}}$ 398040072-001 52-1, Yoyogi-Machi, Shibuya-Ku, Tokyo, Japan. 1980. Bee World, v.60, n.2, p.59-84, 1979.

[2] Peruquetti, RC. Abelhas: milhares de espécies polinizadoras. Informe Agropecuário 13 (149). 1987.

[3] Mariano JS. Extração e caracterização de dois tipos de própolis: verde (mineira) e vermelha (alagoana). Dissertação de Mestrado - Pós-graduação em Engenharia Química da Escola de Engenharia/UFMG. Belo Horizonte/MG. Janeiro de 2014. Disponível em: https://repositorio.ufmg.br/bitstream/1843/BUOSB3PH8V/1/disserta_o_mestrado_proposli s_verde_e_vermelha.pdf

[4] Pereira ADS, Seixas FRMS, Neto FRDA. Própolis: 100 anos de pesquisa e suas perspectivas futuras. Química Nova, v. 25, p. 321-326, 2002. 


\section{Cadernos da Escola de Saúde}

[5] Kumazawa S; Hamasaka T; Nakayama T. Antioxidant activity of propolis of various geographic origins Food Chemistry, v.84, n.3, p.329-339, 2004.

[6] Sforcin JM, Junior AF, Lopes CA, Bankova V, Funari SR. Seasonal effect on Brazilian propolis antibacterial activity. Journal of Ethnopharmacology, v.73, n.1-2, p.243-249, 2000.

[7] Apacame (Associação Paulista de Apicultores Criadores de Abelhas Melificas Europeias). A Própolis de Solução Aquosa. Palestra Dr. Ikukatsu Suzuki, 26 de Julho de 2000. Disponível em: http://www.apacame.org.br/mensagemdoce/58/palestra.htm

[8] Marcucci CM. Propriedades medicinais e terapêuticas dos constituintes químicos da própolis - Instituto de química - Universidade Estadual de Campinas/SP. Química Nova, Vol.19 No.5 529 - v.19 n.512. 2002.

[9] Ministério da Agricultura, Pecuária e Abastecimento (MAPA - BR). Dispõe sobre a Instrução Normativa $n^{\circ} 3$, de 19/01/2001- Regulamento de identidade e qualidade de extrato de própolis, 2001.

[10] Agência Nacional de Vigilância Sanitária (ANVISA - BR). Farmacopeia Brasileira, volume 1. $5^{\mathrm{a}}$ Ed. Brasília, 2010.

[11] Kawakita ET, Souza EA, Uehara DM, Orsi RO. Avaliação da vida útil do extrato hidroalcóolico de própolis mantido sob diferentes temperaturas de armazenamento. ASA. V.3, n.1, p. 33-46, 2015.

[12] Alves E, Kubota EH (2002) Rev. Ciên. FarmBás. Apl. 34:37-41.

[13] Lima CP, Cunico MM, Miyazaki CMS, Miguel, OG, Côcco, LC, \& Yamamoto, CI, et al. (2012). Rev Bras Plant. Med 14:321-326.

[14] Matsuda AH, Melo AAM, Muradian, LBA. Identidade e qualidade a própolis proveniente de quatro regiões do Brasil. Ver. Inst. Adolfo Lutz (Impr.). 71(3): 540-548. Janeiro/2012. 


\section{Cadernos da Escola de Saúde}

[15] Molinaro EM, Caputo LFG, Amendoeira MRR (Org). Conceitos e Métodos para a Formação de Profissionais em Laboratórios de Saúde, v. 4. Rio de Janeiro: EPSJV, IOC, 2009.

[16] Ostrosky EA, Mizumoto MK, Lima MEL, Kaneko TM, Nishikawa SO, Freitas BR. Métodos para avaliação da atividade antimicrobiana e determinação da Concentração Mínima Inibitória (CMI) de plantas medicinais Rev. bras. farmacogn. vol.18 n.2 João Pessoa Apr./June 2008.

[17] Funari CS, Ferro VO. Análise de própolis. Ciênc. Tecnol. Aliment. Campinas, v. 26, n.1, p. 171-178, Mar.2006. Disponível em:

http://www.scielo.br/scielo.php?script=sci_arttext\&pid=S0101$\underline{20612006000100028 \& \operatorname{lng}=\mathrm{en} \& \mathrm{nrm}=\mathrm{iso}}$

[18] Soares ALF, Bilezikjian PJ, Parceli EG, Medeiros PCM, Souza LA. Identidade e qualidade de diferentes extratos de própolis. Revista Gestão em Foco. Edição nº 9. 2017.

[19] Gonsales, G.Z., Orsi, R.O., Rodrigues, P. e Funari, S.R.C. 2005. Análises físico-químicas de extrato alcoólico de própolis. B. Indústr. Anim., Nova Odessa, 62: 215-9. Disponível em: http://iz.agricultura.sp.gov.br/bia/index.php/bia/article/view/1299/1294

[20] Souza E.A., Inoue H.T., Gomes S.M.A., Funari S.R.C., Orsi R.O.. Propriedade físicoquímica da própolis em função da sazonalidade e método de produção. Arch. zootec. [Internet]. 2010 Dic [citado 2020 Maio 26] ; 59( 228 ): 571-576. Disponível em: http://scielo.isciii.es/scielo.php?script=sci_arttext\&pid=S0004-05922010000400010\&lng=es.

[21] Simões CC, Araújo DB, Araújo RP. Estudo in vitro e ex vivo da ação de diferentes concentrações de extratos de própolis frente aos microrganismos presentes na saliva de humanos. Revista Brasileira de Farmacognosia, João Pessoa, v.18, n.1, p.84-89, jan/mar 2008.

[22] Woisky RG. Métodos químicos para controle de amostras de própolis. [dissertação de mestrado]. São Paulo (SP): Faculdade de Ciências Farmacêuticas; 1996. 


\section{Cadernos da Escola de Saúde}

[23] Gregório LE. Influência da sazonalidade na composição polínica, no perfil químico e na atividade antimicrobiana da própolis produzida em Cajuru-SP. [dissertação de mestrado]. Ribeirão Preto (SP): Universidade de São Paulo; 2003.

[24] Lima LSC. Caracterização físico-química e atividades antioxidante e antimicrobiana de própolis produzidas em colônias de abelhas Apis mellifera L. na região Noroeste do Estado do Ceará. [Dissertação de Mestrado]. Instituto Federal de Educação, Ciência e Tecnologia do Ceará. 2015.

[25] Lima AON. Produção de própolis por abelha melífera africanizada (Apis mellifera L.) na caatinga do baixo Jaguaribe cearense. 2012. 92f. Tese (Doutorado em Zootecnia) Universidade Federal do Ceará, Centro de Ciências Agrárias, Departamento de Zootecnia, Programa de Pós-Graduação Integrado em Zootecnia, Fortaleza, 2012.

[26] Silva RA, Rodrigues AE, Ribeiro MCM, Custódio AR, Andrade NED, Pereira WE. Características físico-químicas e atividade antimicrobiana de extratos de própolis da Paraíba, Brasil. Cienc. Rural [online]. 2006, vol.36, n.6, pp.1842-1848. Disponível em: http://www.scielo.br/scielo.php?script=sci_arttext\&pid=S0103$\underline{84782006000600027 \& \operatorname{lng}=\mathrm{en} \& \mathrm{nrm}=\mathrm{iso} .}$

[27] Carratu E, Sanzini E. Sostanze. Biologicamente ative presenti negli alimenti di origine vegetable. Annalidell’ Instituto SuperiorediSanitá. 2005;41(1):7-16.

[28] Horst MA, Cruz A de C, Lajolo FM. Biodisponibilidade de compostos bioativos de alimentos. In: Biodisponibilidade de Nutrientes. Barueri: Manole; 2016.

[29] Asis M. Propóleos: el oro púrpura de las abejas. Centro de Información y Documentación Agropecuaria. Editorial CIDA. La Habana. Cuba. 1989.

[30] Toreti VC. Estudo da influência da sazonalidade sobre algumas propriedades físicoquímicas e biológicas da própolis de dois apiários do estado de São Paulo. Dissertação (Mestrado), 2011. Universidade Estadual de Campinas. Faculdade de Engenharia de Alimentos. Campinas, 2011. 


\section{Cadernos da Escola de Saúde}

[31] Longhini R, Raksa SM, Oliveira ACP, Svidzinski TIE, Franco SL. Obtenção de extratos de própolis sob diferentes condições e avaliação de sua atividade antifúngica. Rev. bras. farmacogn..7(3):388-395. Disponível em: http://www.scielo.br/scielo.php?script=sci_arttext\&pid=S0102$\underline{695 X 2007000300015 \& \operatorname{lng}=\mathrm{en} .}$

[32] Marques, N. Fitoterapia (Coleção Nutrição Clínica e Funcional). $2^{\mathrm{a}}$ ed. São Paulo: Valéria Paschoal Editora Ltda. 2014. p. 107.

[33] Junior LF, Covre YP, Oliveira P, Mikalouski U. Bactéria Staphylococcus aureus. Congresso Multidisciplinar da Faculdade de Apucarana, 2019. Disponível em: http://www.fap.com.br/anais/congresso-multidisciplinar-2019/poster/183.pdf

[34] Nunes KO. Escherichia coli: como uma bactéria do intestino pode causar infecção urinária? - Departamento de Microbiologia - Instituto de Ciências Biomédicas - Universidade de São Paulo (USP), 2018. Disponível em: http://microbiologia.icb.usp.br/cultura-eextensao/textos-de divulgacao/bacteriologia/bacteriologia-medica/escherichia-coli-como-uma bacteria-do-intestino-pode-causar-infeccao-urinaria/

[35] Bush LM, Perez MT. Pseudomonas e infecções relacionadas. Manual MDS - Versão para profissionais da Saúde. Abril/2018. Disponível em: https://www.msdmanuals.com/pt/profissional/doen\%C3\%A7as-infecciosas/bacilos-gramnegativos/pseudomonas-e-infec\%C3\%A7\%C3\%B5es-relacionadas.

[36] Lutz L, Paris FD, Vieira MI, Marques EDA, Barth AL. Bacteriologia da Fibrose Cística. Unidade de Microbiologia, Serviço de Patologia Clínica, Hospital de Clínicas de Porto Alegre (HCPA), Universidade Federal do Rio Grande do Sul (UFRGS). Unidade de Biologia Molecular, Serviço de Patologia Clínica, HCPA. Laboratório de Bacteriologia, Hospital Universitário Pedro Ernesto, Universidade do Estado do Rio de Janeiro. Serviço de Patologia Clínica, HCPA, UFRGS. Porto Alegre, RS. 2011. Disponível em: https://seer.ufrgs.br/hcpa/article/download/21152/12749 


\section{Cadernos da Escola de Saúde}

[37] Gomes, Maria F.F. et al . Atividade antibacteriana in vitro da própolis marrom. Pesq.

Vet. Bras., Rio de Janeiro, v. 36, n. 4, p. 279-282, Abr.2016. Disponível em: http://www.scielo.br/scielo.php?script=sci_arttext\&pid=S0100736X2016000400279\&lng=en\&nrm=iso.

[38] Junior AF et al . Atividade antimicrobiana de própolis de Apis mellifera obtidas em três regiões do Brasil. Cienc. Rural, Santa Maria , v. 36, n. 1, p. 294-297, Feb. 2006 . Disponível em: $\quad$ http://www.scielo.br/scielo.php?script=sci_arttext\&pid=S0103$\underline{84782006000100047 \& \operatorname{lng}=\mathrm{en} \& \mathrm{nrm}=\text { iso }}$

[39] Maia-Araújo YLF, Mendonça LS, Orellana SC, Araújo ED. Comparação entre duas técnicas utilizadas no teste de sensibilidade antibacteriana do extrato hidroalcoólico de própolis vermelha - Scientia Plena - volume 7, num 4. 2011. Disponível em: https://www.arca.fiocruz.br/bitstream/icict/8664/2/Compara\%C3\%A7\%C3\%A3o\%20entre\% 20duas $\% 20 \mathrm{t} \% \mathrm{C} 3 \%$ A9cnicas $\% 20$ utilizadas $\% 20$ no\%20teste $\% 20 \mathrm{de} \% 20$ sensibilidade $\% 20$ antiba cteriana\%20do\%20extrato\%20hidroalco\%C3\%B3lico\%20de\%20pr\%C3\%B3polis\%20vermel ha..pdf 